\title{
How to Manage Collaborative Policy Innovation Networks? Practical Lessons from a Flemish Coastal Protection Initiative
}

\author{
Vidar Stevens \\ Department of Political Science, \\ University of Antwerp, Antwerp, Belgium.
}

Received: October 4, 2017 Accepted: October 23, 2017 Online published: October 28, 2017 doi:10.5296/jpag.v7i4.12078

URL: https://doi.org/10.5296/ jpag.v7i4.12078

\begin{abstract}
Collaborative policy innovation networks are increasingly used as vehicles for fostering innovative policy solutions. However, scholars have noted that the extent to which collaborative networks can actually contribute to the development of innovative policy solutions depends on how they are managed. Empirical research on the management of collaborative policy innovation networks has so far been limited. Therefore, a case is reviewed to add new insights to the link between collaboration, management, and policy innovation. Specifically, the management strategies are examined which helped a Flemish administrative network to develop a radical new Coastal Protection Policy Plan. This study shows that a clear procedural groundwork, playful mediating strategies, and a good people knowledge help network managers to facilitate the development of innovative policy solutions in a collaborative network.
\end{abstract}

Keywords: collaboration, innovation, management, governance, coastal protection

\section{Introduction}

This article examines the management of collaborative processes of public sector innovation in networks. It aims to explore how specific management strategies can accommodate interactions between public actors in networks as a means to radically develop new and bold ideas to change policies and services (Eggers \& Singh, 2009).

Management is in this study understood as, "the micro-level endeavors and interventions of a central actor ('the manager') to facilitate collaborative networks, by shaping the conditions under which these networks operate and the involved stakeholders interact with each other" (Voets et al., 2015: 983). Public sector innovation is interpreted as, "creative search processes 
used to develop and realize new ideas and solutions that radically transform the way in which we are imagining and doing things in the public sector" (Ansell \& Torfing, 2014:4).

The focus on collaborative processes of public sector innovation is very timely because governments are increasingly searching for ways to tame cross-cutting policy issues. One of the ways of many governments has been to establish collaborative networks (Head, 2008; OECD, 2014). Collaborative networks can be regarded as, 'multi-organizational arrangements in which stakeholders work together to solve problems that cannot be solved, or solved easily, by single actors' (Agranoff \& McGuire, 2003: 4). Particularly, the expectation of policymakers has been that more concerted and innovative policy solutions will emerge for cross-cutting policy problems, as more stakeholders and thus more knowledge, resources, and experiences are included in the decision-making processes (Nambisan, 2008: 11).

Despite the high-flying expectations in the innovative capacities of collaborative networks, scholars have argued that the extent to which collaborations can actually contribute to the development of innovative policy solutions for cross-cutting policy problems depends on the manner in which they are managed (Montin et al., 2014). According to these scholars, the micro-level management of collaborative networks is necessary because stakeholders can hold different problem perceptions, may be reluctant to collaborate, or may paralyze the innovation process for strategic reasons (Agger \& Sørensen, 2016; Stevens \& Agger, 2017).

Empirical research on the micro-level management of processes of public sector innovation in collaborative networks has, however, remained scarce (Ansell \& Torfing, 2014: 126; Sørensen, 2014: 10; Stevens \& Verhoest, 2016a; Stevens \& Agger, 2017). This lack of research is striking because it means that we (i.e. 'the scientific community') do not fully understand how managers can live up to their potential in processes of public sector innovation that take place in collaborative networks. In addition, it implies that we do not have a realistic sense of the value of collaborative networks as vehicles for the promotion of innovative policy solutions.

Therefore, in this article, a new empirical case is reviewed to add new insights to the link between management, public sector innovation, and collaborative networks. More specifically, the efforts of a manager in a Flemish administrative network consisting of 12 persons regarding the development of an innovative and new Flemish Coastal Protection Policy Plan (FCPPP) are reviewed by drawing upon document- and interview data.

This article continues as follows. First, the phenomenon of collaborative innovation is introduced. Then, the current state of the art of the management of collaborative innovation networks and the Facilitative Leadership Model of Ansell \& Gash (2012) are discussed. Section five introduces the case specificities and reports the chosen methodology. Section six presents the results of the case analysis. In the final section, the article reflects on the main lessons that can be drawn from this study with regard to the management of collaborative processes of public sector innovation.

\section{Collaborative Policy Innovation in the Public Sector}

There are different forms of public sector innovation. The academic literature mentions 
administrative process innovations, technological process innovations, product or service innovations, governance innovations, conceptual innovations and policy innovations (De Vries, Tummers \& Bekkers, 2015:154; Duijn, 2009:128). This article specifically focuses on the latter category. Policy innovation is by Sørensen and Waldorff (2014:3) defined as: " $a$ deliberate effort of governments to formulate, realize and diffuse new problem understandings, policy visions, and strategies for solving unmet societal challenges."

Nowadays, it is not uncommon that a policy innovation is the outcome of an innovation process that involves a multitude of organizations (Van Buuren \& Loorbach, 2009). The collaborative character of recent policy innovation processes has for the most part been a consequence of the 'wickedness', and the intertwined nature, of many of today's policy issues (e.g. global warming, youth unemployment, poverty, obesity, etc.). Causal relations underlying these policy problems are often numerous and difficult to identify. Developments in one seemingly unrelated policy field can impinge in unpredictable and intricate ways on realities of another policy sector (Ney, 2009). This means that wicked policy problems typically transcend the portfolios of single organizations.

As a result, governments have set up collaborative arrangements as a means to tackle wicked policy problems (OECD, 2014). Here the rationale is that through collaboration across conventional boundaries in the public sector, innovative policy solutions emerge that better fit an intertwined policy context. Sørensen \& Waldorff (2014) have called these processes in which multiple representatives from organizations deliberately interact and participate to come up with innovative policy solutions for complex and intertwined policy problems, 'collaborative policy innovation processes'. This article draws on this interpretation and uses the term 'collaborative policy innovation networks' to refer to the collaborative governance arrangements that are central in these policy innovation processes.

\section{The State of the Art of the Literature of the Management of Collaborative Policy Innovation Networks}

Scholars from planning research and governance studies have pointed out that collaborative policy innovation networks have to be managed to produce innovative policy results (Agger \& Sørensen, 2016; Stevens \& Verhoest, 2016a; Stevens \& Agger, 2017). Agger \& Sørensen (2016), for example, indicated that the management of collaborative networks is necessary because stakeholders can hold different problem perceptions, may be reluctant to collaborate or may paralyze the innovation process for strategic reasons.

The management strategies for exercising indirect control over collaborative networks have already been the subject of considerable research, most notably in the network management and governance literature (e.g. Huxham \& Vangen, 2005; Milward \& Provan, 2006; Agranoff, 2006; Koppenjan \& Klijn, 2004). Most of these studies focused on the management of a specific scenario of interdependency-driven network engagement; that is, the reproduction and optimization of existing services or policy solutions but then in an integrated manner. Innovation, however, entails a clear break from the past, and thereby the radical transformation of existing and failed policy practices, ideas, and solutions (Sørensen \& Torfing, 2011). Or as Stevens \& Verhoest (2016a: 19) state, "within collaborative policy 
innovation processes, upfront participants barely know what to expect; the only certainty they have is that the to-be-developed innovative policy solutions are meant to act a game-changers and radically alter the way in which an intertwined policy problem is addressed."

For that reason, scholars have argued that the management of collaborative policy innovation networks is very different from the management of ordinary networks, as managers must not only steer for integrated results and compromises, but also foster creativity and out-of-the-box thinking among participants to develop radically new policy paradigms, and manage the earlier-mentioned 'unknowns' that surround processes of innovation in the public sector (Bason, 2014).

Empirical research on the management of collaborative (policy) innovation networks in the public sector is, however, still in its infancy (Ansell \& Torfing, 2014: 238). Only a very few scholars have examined the dynamics of collaborative policy innovation networks, and have offered accounts of possible micro-level management strategies that can help managers to facilitate the development of innovative policy solutions or public services (see, for example, Bason, 2014; Stevens \& Verhoest, 2016a, Agger \& Sørensen, 2016, Keast \& Waterhouse, 2014).

Some of the findings and suggestions of these earlier studies are quite contradictory. A good example is a finding of Bason (2014: 220) in comparison to an outcome of the study of Keast \& Waterhouse (2014: 166). According to Bason, distortive management strategies (e.g. putting or even forcing organizations beyond their usual comfort zone) act as catalysts for creativity and innovation in collaborative networks. Keast \& Waterhouse, on the other hand, argue that integrative strategies, which are about encouraging and stimulating the genuine sharing of information among actors without any form of coercion, are most beneficial to spur idea generation in processes of policy innovation.

Nevertheless, the few conducted case studies and quantitative studies have increased our knowledge about the interactive dynamics and the management of processes of innovation in collaborative networks. The studies in the book of Ansell \& Torfing (2014), for example, provided us with more information about the generative mechanisms between collaboration and innovation. Specifically, they have shown that the collaborative capacity to innovate increases if there is 'sufficient' synergy ${ }^{1}$, commitment ${ }^{2}$ and learning ${ }^{3}$ between involved stakeholders in collaborative policy innovation networks. In line, Stevens (2017a) has with the help of the Exponential Random Graph Modelling methodology investigated the determinants that hinder or stimulate learning among stakeholders at the micro-level in collaborative policy innovation networks.

There are, however, still many empirical puzzles that need to be solved (Ansell \& Torfing,

\footnotetext{
${ }^{1}$ Synergy is by Ansell \& Torfing (2014: 11) defined as a social process in which stakeholders bring together complementary resources or capabilities (i.e. resource-sharing).

${ }^{2}$ Commitment, then, is understood as the social process through which actors in groups build consensus and support for a particular policy innovation (Ansell \& Torfing, 2014: 11).

${ }^{3}$ Learning is considered as the social process whereby cognitive change occurs as a result of interaction between different stakeholders, which can transform or reframe the collective sense of possibility or generate new ideas (Ansell \& Torfing, 2014: 11).
} 
2014: 238-239), and various 'accepted' truisms which have to be empirically scrutinized (Stevens \& Verhoest, 2016b). For example, is it always the case that collaboration ensures that public sector innovation draws upon and brings into play all relevant innovation assets in terms of knowledge, imagination, creativity, courage, resources, transformative capacities and political authority (Sørensen \& Torfing, 2012: 5)?

Furthermore, as scholars we need to move beyond the mere development of taxonomies of management roles - and instead focus on the specific micro-level management strategies to see under what circumstances which specific management strategies foster or hinder the development of innovative policy solutions in multi-actor collaborations. Because, up till now, six different taxonomies have been developed: the network management triangle (Stevens \& Verhoest, 2016a), the Innovative-Leadership Model of Termeer \& Nooteboom (2014), the three public design attitudes of Bason (2014), the taxonomy of management roles and tasks of Agger \& Sørensen (2016), the therapeutic management role suggested by Stevens (2017b), and the Facilitative Leadership Model of Ansell \& Gash (2012).

In consequence, we inter alia know that a manager of a collaborative (policy) innovation network has to act as a pilot, whip, culturemaker, communicator, therapist, steward, mediator, or catalyst, and that his or her way of acting must be 'legitimate', lead to 'stability', and ensure the 'efficient generation of a shared agreement'. Yet, what we lack is how exactly, in practice, these roles and management goals have to be taken up by network managers to live up to their potential in processes of public sector innovation that take place in collaborative networks. As such, scholars are encouraged to use existing taxonomies and frameworks and go in prospective studies one step deeper, to see what micro-level management strategies respectively enhance or hinder a network manager's capacities to perform a particular management role to the best of his or her capabilities in collaborative policy innovation networks.

Hence, this article intends to contribute to the scholarly literature by empirically scrutinizing one of the earlier-mentioned network management taxonomies for collaborative processes of innovation. To be more specific, with the help of the Facilitative Leadership Model an empirical case is examined to see what management strategies the network manager respectively used to facilitate the design of innovative policy solutions. In the next section, the Facilitative Leadership Model will be further explained.

\section{The Facilitative Leadership Model}

According to Ansell \& Gash $(2008 ; 2012)$, the core task of a manager of collaborative (policy) innovation networks is to 'help' others to make things happen. 'Others' can here be interpreted as the stakeholders in the collaborative policy innovation network that do not possess the mandate of 'being' the network manager. Ansell \& Gash argue that there are three different roles of managers to help actors make things happen in collaborative innovation processes; as a steward, mediator, or catalyst. These three management roles are the pillars of their Facilitative Leadership Model.

A steward is a manager who facilitates the collaborative network by establishing and 
protecting the integrity of the innovation process (Ansell \& Gash, 2012:6). Although involved actors are encouraged to take ownership in a collaborative innovation process, this often takes considerable work and time. Hence, the task of the steward is to give direction and develop the basis context in which the collaboration can unfold (idem: 7). This will allow a collaboration to turn into an open and inclusive innovation process (idem: 8).

The second role of managers is, according to Ansell \& Gash (2012:11), to serve as mediator or broker between different involved stakeholders. Since stakeholders hold diverse perspectives and interests, they often do not see eye-to-eye. Therefore, managers are called upon to facilitate positive exchanges between different stakeholders through adjudication of conflict, to arbitrate between different positions, to stabilize the conditions for positive exchange, and to promote trust-building.

The third role for managers of collaborative processes of innovation in networks is to serve as catalysts (Ansell \& Gash, 2012:12). The catalytic role goes beyond a mediating role, in the sense, that a manager must engage with the substantive content of interactions and negotiations with the aim of identifying and using opportunities for producing value. The word 'oppurtinity' is key in these practices, as the manager has to 'see' the possibilities and take the risk to push the group of actors into a certain direction to realize something new that is better than the status-quo.

The Facilitative Leadership Model does not assume a hierarchy among the three management roles. Nonetheless, although managers of collaborative processes are called upon to play multiple roles, the salience of these roles may vary with the circumstances and goals of the collaborative policy innovation network. In this article, the focus will be on whether the network manager in the empirical case performed all management roles, and if so, what specific management strategies were utilized to perform these roles, for what reasons, and with what effects. In this way, this article empirically drills down into the management variable and adds to the goal of Ansell \& Gash (2012:1) to develop a contingency model for the management of collaborative networks that are used as vehicles for innovation processes in the public sector. The next section discusses the case specificities and the methodological approach of this article.

\section{Case Specificities and Methodology}

In this article, the focus is on the management practices in a Flemish administrative network consisting of 12 representatives from different departmental organizations and agencies during the development of the Flemish Coastal Protection Policy Plan (FCPPP). The departmental organizations and agencies belonged to two different levels of government (regional and provincial level). The collaborative network can be regarded as an administrative network which was tasked by the political leaders of the two levels of government to prepare a policy document which could launch a political debate on the future challenges and solutions for issues of coastal protection (like coastal erosion, navigation, flood protection and hydrologic issues) in the Flemish region of Belgium.

The administrative network was established in 2015. For this study, the specific focus is on 
an 'innovation episode' between December 2015 and September 2016. During this innovation episode, the members of the administrative network deliberately tried to develop a possible new Flemish Coastal Protection Policy Plan (FCPPP). In a policy document was written that the aim of the collaboration was not to generate and propose more or less the same kind of policy solutions, but rather to change the form, content and repertoire of policy actions, and even to transform the underlying problem understanding, objectives and program theory of the conventional governmental strategies (i.e. a radical transformation). This aim aligns with what Sørensen \& Torfing (2011) regard as a third-order innovative policy change. For that reason, the intention of the process in this administrative network is perceived as a collaborative policy innovation process.

To study the management practices in the administrative FCPPP network, the case study methodology was used. I acknowledge the inherent limitations of using single case studies for extrapolating findings, as was described by George \& Bennett (2005). Yet, I also agree with Flyvbjerg (2011: 305) when he argues that a case study can further scientific development by the force of example. To this end, I do not pretend that the findings are fully generalizable or highly theoretical. However, I am convinced that the reflections in this article are helpful in substantiating the development of theory on the impact of management on the innovative capacity of collaborative policy innovation networks.

For the data collection, this article drew on a detailed process mapping based on an analysis of documents, and a series of interviews. The document analysis included: minutes of the meetings, newspaper articles, position papers and policy documents of the representatives' organizations, (draft) versions of the final policy document, agendas of the meetings, and parliamentary decrees. The relevance of the documents was determined by making a selection based on whether the information in the documents said something new or extra about the different stagnations and breakthroughs of the policy innovation process, the various activities of the manager, and the positions of the actors with regard to the problem situation and possible solutions. The document analysis was complete once data saturation was reached.

Subsequently, the interviews helped to gain more insight into the arguments, opinions, behaviors, ideas, attitudes, and experiences of the members of the network with regard to the need, development and direction of the collaborative innovation process, the interventions of the manager, and the process results. The interviews were semi-structured and the questions concentrated on the key events and insights that followed from the document analysis. In total, thirteen interviews were conducted (the network manager was interviewed twice).

The interviews typically lasted an average of 1.5 hours. Each interview was recorded and transcribed. The respondents were promised anonymity. Therefore, the interviews were numbered and in the text of this article the phrase 'respondent (number)' is used to report quotes from the interviews. The interview data was triangulated by comparing the interview transcripts to each other and to the findings of the document analysis. I followed-up with respondents if I ran into inconsistencies to ask for clarification.

For the coding of both the document- and interview data, the NVivo software program was 
used. The coding process proceeded in two steps. First, the management roles of Ansell \& Gash (2012) were used as grounding concepts to code the documents and the interview transcripts; and, as such, identify and cluster what types of management strategies and interventions were used in the deliberations in the administrative FCPPP network to promote the development of the policy innovation.

In the second coding step the empirical data was coded in such a way that it was retrieved what the reasons were why the manager deployed these management interventions, how the different network members experienced and responded to these management strategies and interventions, and what the eventual effects were of the management strategies on the progress of the collaborative innovation process. The results of the empirical analysis are presented in the next section.

\section{The Management of the Administrative FCPPP Network}

\subsection{Steward}

The results section starts by presenting the findings of the management activities of the network manager as 'steward'. As mentioned, the network manager must as steward give direction and develop the basis context in which the collaboration can unfold (Ansell \& Gash, 2012). In her role as steward, the network manager showed two different faces. In the first instance, she was very proactive and took a lot of initiative to bring actors together. Once the collaboration was underway, however, the network manager did not give any guidance but merely infused the brainstorm with her own ideas about how the coastal area had to be protected.

The initial proactive management style of the network manager had to do with the fact that in the beginning of the process, the network manager was solely responsible for initiating the collaborative policy innovation process. From the political level of the two levels of government, she had gotten the mandate to start the innovation process, but it was still unclear which organizations had to be a part of the inter-organizational and intergovernmental administrative innovation network (respondent 9). Therefore, she started bilateral meetings with single governmental organizations which had shown interest in being a part of the collaboration (respondent 1 and 9). In these bilateral meetings, the network manager wanted to have a response to three specific questions: what the expectations of the organizations were, how many FTEs the organizations were willing to dedicate to the collaborative process, and if the organizations could financially support the activities of the collaborative network (respondent 6). In addition, the network manager insisted that the interested organizations signed a contract to ensure that the organizations could not easily withdraw their support for the innovation process if it did not go the way they expected (respondent 4, 6 and 11).

The network manager further made the decision to choose for a so-called LABO-format, which was an often used policy design instrument which allowed civil servants to think about long-term policy plans and solutions without having to consider existing policy plans, law texts, and jurisprudence (respondent 1). Such a LABO-format was a perfect instrument to discuss radical new coastal protection policy solutions without too much interference from 
politicians, like Ministers or cabinet members (respondent 6). The decision to choose for a LABO-format could count on a lot of approval by the network members, because, according to respondent 5, this gave the civil servants the discretionary space to speak more freely, openly, and out-of-the-box about matters of coastal protection.

A point of critique, however, on the behavior of the network manager during these initial bilateral talks was that the individual organizational representatives had little idea of why other organizations were interested in the joining the collaboration (respondent 8). For a large part, the bilateral talks were one-way conversations, where the representatives simply had to respond to the questions of the network manager. In consequence, most information about what had been said and discussed, and what promises were made by the network manager during these bilateral talks, remained unknown for the majority of the representatives of the collaborative policy innovation network (respondent 11).

That being said, respondent 11 remembered that the network manager was in the bilateral talks very inspiring. The network manager created a lot of pictures about the 'good things' that could be achieved by working together, for example, a more uniform coastline system, improved and better protected coastal neighborhoods (urban revitalization projects), or better services (integral coastline protection programs). The promise that was inherent in these pictures was very appealing to many (potential) network members (respondent 1, 4 and 5). As such, despite the fact that the representatives did not know which other parties joined the collaboration, they went to the first meeting with a lot of enthusiasm and high aspirations to make the coastal protection policies future-proof (respondent 8).

During the first general meeting, the representatives saw their network alters for the first time. For most representatives, there was the awareness that the potential of the network would only be achieved if members (and their home organizations) made a genuine commitment to working together (respondent 8). A key strategy to sustain this commitment would be the development of rules that guide actors' interactions and behaviors. Therefore, each person who attended the first meeting looked expectantly at the network manager to tell them more about the time planning, process steps, and working methods within the administrative FCPPP network (respondent 11).

Remarkably, the network manager did not give any guidance. According to respondent 4, "the network manager did not tell the network members how the collaboration would proceed, how the discussions would be organized, and what the final document must look like." Instead, she mainly started discussing her own plans for protecting the coastal system, without creating an open dialogue. According to respondent 11 and 8, the network manager had many good ideas but she pressed us to collect data and information that would support her views on the coastal planning problemacy and possible solutions. In this way, her coastal vision could serve as a basis for the future plans for the coastal planning policies (respondent $3)$.

As a consequence of this, what respondent 11 called, 'non-collegial' managerial behavior, in the first four sessions of the collaborative process many network members felt rudderless. The network members were only speaking in little rounds and looking how their own ideas 
aligned with those of the network manager. In addition, the amount of frustrations of the network members rose rapidly. Some of these frustrations had to do with the fact that the collaborative process was getting nowhere. However, most frustrations had to do with the 'non-collegial' behavior of the network manager (respondent 4 and 8). For that reason, two network members stayed after the fourth meeting to ask the network manager to rethink her stewarding role. They insisted that she would create a more open and inclusive policy process.

In between the fourth and fifth meeting, the network manager had various telephone conversations and email correspondences with these two representatives who had urged her to reconsider her managing role (respondent 5). In these conversations, it became clear that the network manager did not feel very comfortable in her role as network manager (respondent 1). Normally, she would just be one of the representatives, but now she had to sit at the head of the table. She thought that in her stewarding role she could still 'leave her mark' on the policy document, but she did not exactly know how to organize a collaboration. As a result of these 'small talks', the network manager eventually agreed to take a step back and let another network member be the new leader of the collaborative arrangement. The 'former' network manager was also no longer a member of the collaborative network to avoid that the 'leadership change' would have a negative effect on the interactive dynamics in the administrative FCPPP network (respondent 1 and 4).

\subsection{Mediator}

The new network manager had clear ideas about how to turn the tide and let creativity flourish in the collaborative policy innovation network (respondent 4). As a first managerial act, she organized a group-therapy session where every network member could voice their concerns and indicate what they wanted to see changed in the process. Some of the network members found the 'group intervention' intimidating at first, but after the session, most members were surprised how rewarding this group experience was (respondent 8).

During this group-therapy session, three particular things became clear for the (new) network manager. First of all, the responses of the network members confirmed that also other representatives had doubts about the capacities of the former network manager (respondent 5, 9, and 11). Secondly, between the network members, there were quite some knowledge conflicts or gaps. As respondent 11, for example, noted: "I had no background in the concept of circular economy, and despite the fact that some people made an enthusiastic plead for using activities of circular economy to revive the coastal areas and make them future-proof, I found it extremely difficult to understand how this would save our dikes, coastal cities, or rural hinterlands." What frustrated her was that this 'expert of the circular economy' did not make any effort to make his contributions to the deliberations more understanding for others. As a result, she had the feeling that the energy immediately sapped out of the discussions when this 'expert' member started to talk.

Thirdly, there were certain power and goal conflicts between the members of the administrative FCPPP network (respondent 4). In the collaborative innovation network, the network manager had to deal with departments from different layers of government, which 
had different Ministers from different political parties. Although, the network manager avoided turning the innovation process into a political game, by inter alia keeping the network a mere administrative network and using the earlier-discussed LABO format, she noticed that most of the representatives in the administrative FCPPP network had difficulty in looking beyond what their senior administrative leaders, cabinet members, and Ministers would think about specific subject matters. In consequence, the deliberations in the administrative FCPPP network were oftentimes intense debates about different time-horizons, policy directions, redistribution of responsibilities, and the breadth of the collaborative policy innovation process (respondent 3, 7 and 9). In addition, network members experienced that certain network alters acted as if they had more right to be a part of the collaborative policy innovation network than others (respondent 11 and 12).

As such, there was a huge mediating assignment for the new network manager. She not only had to resolve the knowledge differences between the network members, but she also had to appease tensions regarding the power- and goal asymmetry in the administrative network. According to respondent 8 , "the network manager was not the kind of person who used force, like a harsh tone of speech or strong words, to make the network members collaborate and develop transformative policy ideas." Instead, she used different kinds of playful group exercises and discussion formats to allow network members get more appreciation for another's point of view.

To solve the knowledge conflicts or knowledge gaps between network members, the network manager had two playful strategies. First of all, the network manager used the sixth and seventh session to organize small TED talks (respondent 7 and 11). In these meetings, each organizational representative was asked to either present an idea with a compelling new argument behind it which challenges conventional wisdom and practices, or introduce a surprising new service or invention that their network alters had probably not yet heard of. The representatives could only present for five to ten minutes. As such, their presentations had to be very clear and specific. The material from the presentations was, subsequently, used as one of the inputs for the final policy document (respondent 4).

A second strategy which the network manager introduced to reduce the knowledge differences between network members was 'to get visual' (respondent 7). That is to say, the network manager urged the members to solve ambiguities by drawing on papers, sketching diagrams and figures, or developing mind-maps (respondent 4). The network manager believed representatives would more easily break through lingering discussions if ideas and statements were turned into figures, maps, and pictures. Hence, by stimulating the network members to make their plans, concerns, and ideas more visual the network manager hoped that this would boost the imagination of the representatives in the administrative FCPPP network and resolve any misunderstandings or knowledge gaps (respondent 5).

These two mediating strategies had a positive effect. After the two TED talk meetings, representatives had a better idea of what each partner could contribute to the discussions or what someone else's expertise was (respondent 9 and 11). Moreover, many representatives automatically started to prepare as 'homework assignments' all kinds of figures, drawings 
and diagrams to clarify their contributions to the discussions (respondent 7). To this end, the idea of 'getting visual' became a routine working method in the collaborative network.

To resolve issues of power- and goal asymmetry in the collaborative network, the network manager used other playful strategies. After the TED-talk meetings, she did not immediately press for results (respondent 4). It was not her goal to agree on a policy plan as soon as possible. Instead, she wanted to take the time to brainstorm on a wide range of issues, in the hope that the deliberations would not turn into a 'trenchwar' between different organizational and governmental interests (respondent 11). Hence, every new meeting she started with sharp and edgy statements that urged the network members to look beyond their 'organizational logics' and express their personal issues about certain policy problems (respondent 7). Examples of these statements were: how can we protect the Flemish coast if half of it will be flooded by 2050 , or which coastal regions will give us the most economic growth if we can only invest a limited amount of money in our coastal areas? Only when the deadline for drafting the final policy document came up, the network manager started to funnel the brainstorm and search for common ground in the network members' contributions.

One of the big problems the network manager, however, encountered was that many network partners believed that they were very open towards the idea of 'brainstorming', while in reality, they were not (respondent 4). According to the network manager, "most representatives simply wanted to discuss matters at the decision-making table in a clockwise manner, where everybody was given a separate turn to highlight in five minutes what their ideas and concerns were." This was the routine procedure in ordinary meetings. Therefore, besides her strategy to infuse the deliberations with sharp and edgy discussion statements, she introduced another set of playful working methods to not kill the brainstorms. Examples of these playful working methods were: use post-its to simply write down all the remarks and ideas participants had, insist that the representatives were only allowed to leave the room when they as a group had written down 30 or 40 new policy plans, do a small 'tribunal' debate between two representatives with opposing ideas where each of them would try to convince the other network members (who served as audience in these small debates), and celebrate the efforts of representatives by awarding every meeting one member with the title 'innovator of the day' (respondent 7).

A particularly effective method to move beyond entrenched organizational positions and identify joint interests turned out to be the technique of persuasive dialogue (respondent 11). The network members had to move around the room and seek for information about the network alters' underlying core beliefs, goals, desires and preferences. The conversations were supplemented with experts in identified subject areas who presented certain facts and figures about discussion issues (respondent 1). According to respondent 11, this conversation technique helped network members realize that their views, and those of their network alters, were often not grounded in facts but in emotions and routines. Hence, with these persuasive dialogues members discovered the true causes of their conflicts, which, in turn, allowed them to search for possible ways of moving forward (respondent 1).

Respondent 5 argued that eventually these playful ways of interacting made that 
representatives were again looking forward to coming to the network meetings. They had a whole different perception with regard to the possibilities in the collaborative process, compared the dynamics during the first four network meetings. In addition, respondent 7 said that as a consequence of these playful methods representatives began to develop a sense of community, "it felt as if we were not only searching as explorers for innovative ways for governments to deal with new (but still unknown) challenges ahead, but also innovating our working methods to achieve results." Hence, it seemed as if the network manager, with her mediating efforts, had changed the negative momentum into a situation where the network members were more open and willing to generate new insights and policy views through collaboration.

\subsection{Catalyst}

For a collaborative process to turn into an innovative endeavor, it is not merely enough that network members work in harmony towards a shared agreement. A network manager must see to it that members use their creativity and imagination to develop solutions that move beyond conventional wisdom and practices. Therefore, Ansell \& Gash (2012) identified the role of 'catalyst' as a third management role in their Facilitative Leadership framework. A network manager who acts as catalyst engages with the substantive content of interactions and negotiations with the aim of identifying and using opportunities for producing value, in the sense, that solutions are developed that cannot be achieved by one organization solely.

Within the empirical case, the (new) network manager was, however, not really the person who actively shared her ideas, views, and opinions, or reframed discussions in such a way that intractable policy conflicts were turned into win-win solutions (respondent 4). Respondent 7 noted that instead, the network manager possessed another valuable trait which helped her to catalyse the innovation process: she had good 'people knowledge'. With 'people knowledge' respondent 7 meant, "that the network manager had a good eye for what role individuals could play in the collaborative policy innovation network, how each representative could be encouraged to live up to their (role) potential, and at what point in the discussions certain representatives had to be connected or disconnected to ensure breakthroughs in the development of new innovative policy solutions."

Especially, in the final three meetings of the collaborative process, she tried to manage and link the individuals in such a way that high-quality policy solutions were designed (respondent 5). In the previous meetings, the network members had with the TED-talks, the sharp and edgy statements, and the persuasive dialogues, already discussed a whole range of ideas surrounding the topic of coastal protection (respondent 1). Now it was time to connect the dots and let the network members turn their ideas into integrated and innovative solutions that would provide decent responses to the future challenges of the Flemish coast. To this end, respondent 7 described the final three meetings as a kind of 'puppet-game', where the network manager as 'puppet-master' moved the 'right type of representative' into positions from where they (as a group) could effectively decide on what would be written down in the final policy document.

According to respondent 7, “the network manager's puppet game was an interaction between 
visionary representatives, devil's advocates, specialists, and pulse-takers." For each of these four 'types of network members', the network manager used another management approach to make them feel most comfortable with their expected roles in the deliberations. Respondent 7 regarded himself as a visionary representative. He was capable of telling clear stories about how the big transformations within the policy field of coastal planning could look like by the year 2050 and beyond. The visionary people were in the final stages of the collaborative process very important to connect (discussed) innovative ideas of earlier meetings into coherent policy stories. The disadvantage of these visionary representatives, however, was that their contributions were oftentimes very abstract and non-specific (respondent 11). Hence, as soon as network members started to look for more detailed policy solutions to turn the broad policy stories into reality, the network manager was more strict on the contributions of these visionary representatives to the discussions (respondent 4).

The devil's advocates were the representatives who always wondered what all these out-of-the-box ideas would cost and what in practice these innovative solutions meant for the way in which the government (across the different governmental layers and policy sectors) had to reorganize itself (respondent 7). Oftentimes, there were asymetrical policy discussions between the visionary representatives and the devil's advocates (respondent 1). Nonetheless, the antagonism of the devil's advocates was a valuable tool to check whether an innovative idea was a great solution to coastal problems, or whether these were just solutions for made-up problems (respondent 11). Hence, the network manager used these devil's advocates to keep questioning the necessity and possible succes of proposed innovative policy ideas (respondent 4).

The so-called 'specialist' were the representatives who knew everything about laws, parliamentary decrees, political tensions, or technological developments (respondent 7). According to the network manager, "innovating is not just about thinking out-of-the-box - at a certain point in the design-phase the discussion turns into whether the innovative idea can be implemented in the current policy constellation, and if not, what changes are necessary to make the innovation happen." At these moments in the deliberations, it was thus great to have specialists on board, as their knowledge about, what respondent 1 called the 'nitty-gritty policy details', helped the administrative FCPPP network to propose solutions that were not mere 'policy dreams' but which also included a roadmap of how these ideas could be implemented. In particular, the network manager used the specialist to write the policy proposals down in the final document (respondent 4).

The fourth, and final, type of representative which the network manager distinguished were the 'pulse-takers' (respondent 7). In the collaborative network, there were two people who made sure that in the discussions there was also an eye for the human factor. With human factor, respondent 7 meant, what the consequences were of the proposed policy plans for the people living and working in the coastal areas. During the discussions on innovative new policy plans, most representatives talked about the economic activities, infrastructure, and residential areas in the coastal areas. However, they sometimes forgot when they, for example, discussed possibilities to flood certain villages for the protection of the rest of the Flemish coast, that in these villages citizens lived (respondent 9 and 11). The network manager, 
therefore, frequently asked the pulse-takers to comment on whether the discussed proposals were relevant for the citizens living in the coastal areas (respondent 4). Furthermore, the network manager requested the pulse-takers in the final stage of the collaborative process to organize several field trips to give the other network partners a better sense of the problemacy and living conditions in the coastal area (respondent 11).

According to the respondent 8 , "it is hard to exactly pinpoint how we went from discussing innovative ideas to a policy document that was supported by all network members." The network manager argued that, in the end, the network members did most of the work. Respondent 7, however, remarked that you should not underestimate the effect of the 'puppet-play' of the network manager in the final stages of the collaborative process. "By linking the right people at the right time in the discussions, the transformative ideas which each of us had during the brainstorm sessions, were not diminished to unimaginary and conventional policy compromises", argued respondent 7 .

What further helped the final deliberations was that the network manager had prepared a long-list of issues and ideas on the basis of what had been suggested in the brainstorm sessions (respondent 1). With this long-list, the final deliberations started. The network manager had also given the members the assignment to elaborate on only five to ten transformative policy ideas to keep the final document tangible and readable for the policymakers (respondent 5). In consequence, the network members could use the long-list to connect certain themes and solutions or cross out ideas that were not relevant, unrealistic or too hard to achieve (respondent 12). After the last meeting, the network manager edited, together with the specialists, the final document before it was sent to the political leaders of the two involved governmental levels.

Looking back on the collaborative process, respondent 1,7 , and 11 were convinced that the innovative potential of the collaborative process was not fully exploited. They argued that this was mainly a consequence of the bad start in the first four sessions. Moreover, the final weeks were very time-demanding. Within twenty days the final three sessions were planned. In these final sessions, the network members had to decide on all policy solutions which would be included in the final policy document and write down all texts. In the view of respondent 8, this left too little time to reconsider the 'innovativeness' of the included proposals.

Nevertheless, respondent 5 noted that the new network manager definitely changed the interactive dynamics in the collaborative arrangement. Furthermore, the network members proved to be capable to deliver in four months' time a document to the political leaders which dealt with the question of the future challenges of the Flemish coast. On the final interview question, whether she would do things differently if she could change the past, the network manager responded that this was not the case, "because management is always context-specific, and this time the context demanded me to step up and alter the momentum of the collaborative process to ensure that an intergovernmental policy agreement was still reached." 


\subsection{Ambassador}

So far, the case results have shown how the network manager performed the roles of steward, mediator, and catalyst. However, from the empirical data, it became clear that the network manager also 'acted as an ambassador'. A network manager acting as ambassador should here be understood as a person who represents the (members of the) collaborative policy innovation network in encounters with external stakeholders. In particular, the network manager invested a lot of her time in remaining on good terms with the nineteen coastal municipalities (respondent 12). In the administrative FCPPP network, organizations from the local level were not included. Yet, the network manager had her specific reasons to keep in touch with all local coastal municipalities.

According to respondent 12, in an earlier collaborative innovation process regarding issues of coastal protection, the involved governmental organizations had completely disregarded the wishes and demands of the local (coastal) municipalities. In fact, no mayor or alderman of any local municipality was invited to join the deliberations in the earlier collaborative process nor updated on the process. The aim of this earlier collaborative process was to provide the Flemish government with various scenarios about how the coastal region could look like by the year 2100 (Vlaamse Bouwmeester, 2013). In total, four scenarios were developed in this earlier collaborative policy innovation process. One of the developed scenarios was very extreme; in the sense, that it suggested that it was the best solution to intentionally flood half of the Flemish coastline to protect the rest of the Flemish cities and municipalities (Atelier Visionaire Kust, 2014). As soon as the results of this earlier collaborative policy innovation process were presented to the press, most of the coastal municipalities (especially, those which were selected to be flooded) torpedoed the policy idea and insisted that no administrative organization continued discussions about future plans for the coastal area without consent and involvement of the local coastal municipalities (De Redactie, 2015). Hence, the network manager of the administrative FCPPP network utilized various strategies to ensure that the municipalities this time did not have the feeling that they were overlooked.

Two specific management interventions were identified in the empirical analysis. First of all, respondent 1 noted that before the deliberations in the administrative FCPPP network started, the 'former' network manager visited all nineteen municipalities. On the one hand, the network manager did this to allow the local municipalities to share their concerns and frustrations about the previous innovation process. On the other hand, the network manager wanted to use these conversations to obtain more information about the expectations of the local municipalities regarding the new collaborative process, and what the municipalities currently were doing regarding matters of coastal protection. Respondent 1 joined the network manager on these visits. He explained: "with these visits we got a better idea of what the municipalities could do on their own (and were already doing) and what problems were too big for a single municipality and which had to be addressed on a bigger scale by collaborations with other municipalities and governmental layers." Secondly, during the deliberations of the administrative FCPPP network, the local municipalities were every two months updated on the progress of the collaborative innovation process. If the local municipalities did not agree with certain ideas or policy suggestions, the network members 
tried to look for other ways to make the local municipalities feel more comfortable with the proposed policy directions (respondent 1).

Respondent 12 had the feeling that the local municipalities appreciated these management actions (of the manager as ambassador) very much. According to him, "you could notice that we [read: the members of the administrative FCPPP network] regained the trust of most of the mayors and alderman of the local coastal municipalities." The local municipalities more often shared information and policy documents with the members of the administrative FCPPP network (respondent 4). The ambassador's role of the network manager was, however, very demanding. Respondent 1 explained, "visiting nineteen municipalities was very time-consuming and did not always fit the agenda." In his view, keeping the local municipalities updated did not have a negative impact on the deliberations in the administrative FCPPP network. The local municipalities did not have major demands. They just wanted to be recognized as relevant decision-making partners. Hence, the network manager mainly saw the management of the external network dynamics as a necessary endeavor to avoid that all hard work by the representatives of the administrative FCPPP network would have been for nothing (respondent 4).

\section{Discussion and Conclusion}

To conclude, research on the micro-level management of collaborative policy innovation networks has been limited. Therefore, this article's focus was on the micro-level management strategies the manager of a Flemish administrative network utilized to facilitate the development of an innovative coastal protection policy plan. The taxonomy of management roles of Ansell \& Gash (2012) was used as a heuristic to cluster the management strategies, to see how the manager performed each of the management roles, and to determine which micro-level management interventions respectively enhanced or impeded the collaborative process of policy innovation in the empirical case.

What definitely can be learned from the empirical case is that although managers of collaborative policy innovation processes are called upon to play multiple roles, the relative prominence of the different roles may vary with the antecedent conditions and circumstances in the collaborative network. Specifically, we have seen in the empirical case the salience of the mediating network management role, since the network members felt extremely frustrated and rudderless as a consequence of a lack of guidance and support by the network manager in the beginning of the innovation process.

The most important contribution of this article is the identification of a fourth management role for the model of Ansell \& Gash (2012): the role of ambassador. In the coding of the empirical data, it was difficult to connect the network management interventions with stakeholders 'outside' the administrative FCPPP network to any of the three (original) management roles. I argue that this is due to the inward focus of the Facilitative Leadership Model. With inward focus, I mean a focus on how the collaborative network as a 'closed entity' operates, and has to be managed, without having an eye for the external network dynamics. Of course, Ansell \& Gash (2012: 8) argue that a process must be open and inclusive but they do not account for the moments when a network manager, as a 
'representative' of the whole collaborative arrangement, visits and interacts with external stakeholders to ensure that the 'internal network dynamics' are not hindered or obstructed. To this end, I believe that the management role of the ambassador is a valuable addition to the Facilitative Leadership Model.

Furthermore, for each network management role, a particular lesson stands out in this article's empirical case. The first lesson follows from the way in which the network manager performed the role of steward. In the empirical case, the network manager did a great job in activating the network members to join the collaboration. However, activating network members did not immediately imply that they all stepped up and actively engaged in determining the course and direction of the joint effort. The network members were not yet comfortable with the idea of working together, and they had no clear groundwork (i.e. rules, planning, and process steps) from where they could start the collaboration. The network manager did not see it as her primary task to give guidance to the collaboration; instead, she mainly used the collaborative process to spread her own ideas about how the coastal area had to become future-proof. In consequence, the network members kept in the first four sessions talking in little rounds without having the feeling that they were getting somewhere.

Therefore, on the basis of these case dynamics, I advise network managers during the initial phase of network formation and initiation, to use a hands-on management approach, and provide network members with enough clarity about the innovation process by making clear procedural decisions (Sørensen and Torfing, 2011). This gives the network members the time to grow a sense of connectedness and network loyalty. From thereon, network members can expand their shared activities regarding the development of innovative policy solutions which, eventually, allows the manager to take a step back as soon as the network members show that they are capable of determining the course of the innovation process by themselves.

This first lesson has some resonance in the collaborative innovation literature. Stevens \& Verhoest (2016a), Agger \& Sørensen (2016), and Bason (2014) respectively argue that the potential for innovation increases if, especially in the beginning of the innovation process, the network manager steers the innovation process. In the beginning, the network members actors are faced with a lot of uncertainty. The only certainty they initially have is that the eventual policy plan must act as a game-changer and radically alter the way they are doing things. Hence, a steering network manager can help involved network members at the start of the innovation to adapt to the 'unknows' that surround processes of collaborative innovation.

A second lesson relates to the management role of the mediator. In the empirical case, the new network manager had a huge mediating assignment. As a substitute network manager, she had to turn a negative momentum characterized by frustrations about the previous network manager and knowledge gaps and goal- and power-asymetries between network members into a situation where network members on equal-footing would develop policy solutions which moved beyond conventional wisdom and practices. In addition, she had to deal with the expectation of different network members that discussions would take place in a clockwise manner, where everybody was given a separate turn to share their ideas and 
concerns.

To mediate between network members, the network manager did not use a forceful management style, like a harsh tone of speech or strong words. Instead, she utilized different playful group exercises and discussion formats. In the results section, various of these playful working methods were discussed. For many network members, these playful ways of interacting were very different from how they normally communicated in collaborative networks. As a consequence of the playful working methods, the network members began to develop a sense of community, since they were not only searching for innovative ways for governments to deal with future challenges of coastal protection, but also innovating their working methods to achieve results. In addition, due to the different playful conversation techniques, it became more easy for network members to notice that their views were often not grounded in facts but rather in emotions and routines. Altogether, this made network members more open to discovering the true causes of their organizational conflicts and more willing to search for possible ways to collaboratively move forward. Hence, I argue that by also 'innovating' the working methods in a collaboration, a manager can foster the creativity and the willingness of network members to work jointly towards innovative policy solutions.

Similar case dynamics and mediating solutions can be found in the empirical innovation study of Keast \& Waterhouse (2014). They pointed out that we (as 'scholars') cannot escape the reality that an innovation process is not without power conflicts and negotiations. However, by depoliticizing the decision-making process and without force finding light-hearted ways to encourage network members to look beyond their entrenched organizational positions, they claim that idea generation can most optimally be spurred in processes of policy innovation (Keast \& Waterhouse, 2014: 166).

With regard to the third management role of the Facilitative Leadership Model of Ansell \& Gash (2012) - that of the catalyst - this empirical study presents another way to create 'collaborative value', i.e. create innovative policy solutions that cannot be achieved by a single organization solely. Ansell \& Gash (2012: 12) argue that a network manager must engage with the substantive content of interactions and negotiations with the aim of identifying and using opportunities for producing innovative results in collaborative processes. In this article's empirical case, however, the network manager was not the person who substantively engaged in the policy discussions.

She instead used a kind of puppet-play, where she as a puppet-master, moved the right persons in the right positions at the right moments in the deliberations to ensure that innovative ideas were turned into coherent and comprehensive policy stories. The network members had different ways to communicate and different personality traits. Some people were good in acting as a devil's advocate, whereas others were capable of telling clear stories about how the big transformations within the field of coastal planning and protection could look like by the year 2050. Thus, by connecting the right network members, or terminating interactions when necessary, the network manager was capable to ensure that the transformative ideas of all network members were eventually not diminished to unimaginary and conventional policy compromises. Hence, the third, and final, lesson that can be learned 
from this empirical case is that 'people knowledge', and the right use of this knowledge in connecting or terminating relationships, is another helpful managerial asset to catalyse the production of collaborative value in processes of policy innovation.

Of course, this research also has certain limitations. In the article, the small-N problem of a single case study, and thereby the issue of context-dependent generalizations, was already addressed. Additionally, because the management of a collaborative policy innovation process where the network members eventually achieved to develop a policy plan was only studied, and not compared to a case where the actors with the help of a manager did not agree on an innovative policy solution, the results and final reflections of this article may have some bias. In consequence, the micro-level managerial approaches that are suggested to be most beneficial given the complex institutional dynamics of the collaborative policy innovation network can have a smaller positive influence on the interactions between network members than is proclaimed.

Therefore, I, first of all, propose that prospective studies examine the management of collaborative networks where the involved actors did not succeed in agreeing on innovative policy solutions. Such an analysis would verify or falsify the research findings for the different management roles. Secondly, I advise scholars to also look at other complex innovation- and governance contexts. It would, for example, be interesting to see how the management dynamics for the promotion of policy innovations in collaborative networks that operate within a single governmental level differ from the case findings of this empirical article. Thirdly, I encourage scholars to also empirically scrutinize other developed taxonomies of management goals and roles. In this way, the research niche of the management of collaborative policy innovation networks can further mature, and thereby enrich the scholarly debates about how under varying circumstances network management can spur collaborative processes of policy innovation in the public sector.

\section{Acknowledgments}

This work was supported by the Belgian Science Policy under grant BR/132/A4/BRAIN-TRAINS.

\section{References}

Agger, A., \& Sørensen, E. (2016). Managing Collaborative Innovation in Public Bureaucracies. Planning Theory. https://doi.org/10.1177/1473095216672500

Agranoff, R. (2006). Inside Collaborative Networks: Ten Lessons for Public Managers. Public Administration Review, 66(special issue), 56-65. https://doi.org/10.1111/j.1540-6210.2006.00666.x

Agranoff, R., \& McGuire, M. (2003). Collaborative Public Management: New Strategies for Local Government. Washington, DC: Georgetown University Press.

Ansell, C., \& Gash, A. (2008). Collaborative Governance in Theory and Practice. Journal of Public Administration Research and Theory, 18(4), 543-571. https://doi.org/10.1093/jopart/mum032 
Ansell, C., \& Gash, A. (2012). Stewards, mediators and catalysts: Toward a Model of Collaborative Leadership. Innovation Journal: The Public Sector Innovation Journal, 17(1), $1-21$.

Ansell, C., \& Torfing, J. (2014). Collaboration and design: new tools for public innovation. This is a chapter. In C. Ansell \& J. Torfing (Eds.), Public Innovation through Collaboration and Design (pp. 1-19). New York, N.Y.: Routledge.

Atelier Visionaire Kust. (2014). Eindrapport Fase 3 deel 2: Exploratief ontwerpend onderzoek. Retrieved from the Ruimte Vlaanderen website:

http://doc.ruimtevlaanderen.be/rapport/20150226-MKL2100-Eindrapport-Deel2_.pdf

Bason, C. (2014). Design attitude as an innovation catalyst. This is a chapter. In C.Ansell \& J. Torfing (Eds.), Public Innovation through Collaboration and Design (pp. 209-229). New York, N.Y.: Routledge.

De Redactie. (2015). Wordt Belgische Kust op termijn in tweeën gedeeld?. Retrieved from the De Redactie website: http://deredactie.be/cm/vrtnieuws/regio/westvlaanderen/1.2299628

De Vries, H., Bekkers, V., \& Tummers, L. G. (2015). Innovation in the Public Sector: a Systematic Review and Future Research Agenda. Public Administration, 94(1), 146-166. https://doi.org/10.1111/padm.12209

Duijn, M. (2009). Embedded Reflection on Public Policy Innovation; a relativist/pragmatist inquiry into the practice of innovation and knowledge transfer in the WaterINNovation program. Dissertation published by Eburon.

Eggers, W. D., \& Singh, K. S. (2009). The Public Innovator's Playbook: Nurturing Bold Ideas in Government. Washington, DC: Harvard Kennedy School of Government.

Flyvbjerg, B. (2011). Case study. This is a Chapter. In N.K. Denzin, N. K. \& Y.S. Lincoln (Eds.). The Sage Handbook of Qualitative Research. Thousand Oaks, CA: Sage.

George, A. L., \& Bennett, A. (2005). Case studies and theory development in the Social Sciences. Cambrige, MA: MIT Press.

Head, B. W. (2008). Assessing network-based collaborations: effectiveness for whom? Public Management Review, 10(6), 733-749. https://doi.org/10.1080/14719030802423087

Huxman, C., \&Vangen, S. (2005). Managing to Collaborate; The Theory and Practice of Collaborative Advantages. London: Routledge.

Keast, R., \& Waterhouse, J. (2014). Collaborative networks and innovation: the negotiation-management nexus. This is a chapter. In C. Ansell \& J. Torfing (Eds.). Public Innovation through Collaboration and Design (pp. 148-170). New York, N.Y.: Routledge.

Klijn, E. H., \& Koppenjan, J. (2004). Managing Uncertainties in Networks. New York, N.Y.: Routledge.

Milward, H. B., \& Provan, K. G. (2006). A Manager's Guide to Choosing and Using 


\section{Mll Macrothink}

Journal of Public Administration and Governance ISSN 2161-7104 2017, Vol. 7, No. 4

Collaborative Networks. Retrieved from the IBM Center for the Business of Government website: http://www.srpc.ca/ess2016/summit/Reference_9-Milner.pdf

Montin, S., Johansson, M., \& Forsemalm, J. (2014). Understanding innovative regional collaboration: metagovernance and boundary objects as mechanisms. This is a chapter. In C. Ansell \& J. Torfing (Eds.). Public Innovation through Collaboration and Design (pp. 106-125). New York, N.Y.: Routledge.

Nambisan, S. (2008). Transforming government through collaborative innovation. Public Manager, 37(3), 36-41.

Ney, S. (2009). Resolving Messy Policy Problems; handling conflict in environmental, transport, health, and ageing policy. London, UK: Earthscan.

OECD. (2014, November). Innovating the Public Sector; From Ideas to Impact. Paper presented at the OECD Conference, Paris, France.

Sørensen, E. (2014). The Metagovernance of Public Innovation in Governance Networks. Paper presented at the Policy\& Politics Conference, Bristol, UK, September 16-17.

Sørensen, E., \& Torfing, J. (2011). Enhancing Collaborative Innovation in the Public Sector. Administration and Society, 43(8), 842-868. https://doi.org/10.1177/0095399711418768

Sørensen, E., \& Waldorff, S. B. (2014). Collaborative policy innovation: Problems and potential. The Innovation Journal: The Public Sector Innovation Journal, 19(3), 1-17.

Stevens, V. (2017a, in press). Individual learning behaviour in collaborative networks. This is a Chapter. In C. Dunlop, C. Radaelli, \& P. Trein, Learning in Public Policy: Analysis, Modes and Outcomes. Palgrave-MacMillan, Basingstoke, United Kingdom.

Stevens, V. (2017b). Discussion: The Network Manager as Therapist. Journal of Public Administration and Governance, 7(3), 118-122. https://doi.org/10.5296/jpag.v7i3.11658

Stevens, V., \& Agger, A. (2017). Managing Collaborative Innovation Networks - Practical Lessons from a Belgian Spatial Planning initiative. Journal of Public Administration and Governance, 7(3), 154-173. https://doi.org/10.5296/jpag.v7i3.11748

Stevens, V., \& Verhoest, K. (2016a). How to Metagovern Collaborative Networks for the Promotion of Policy Innovations in a Dualistic Federal System?. The Innovation Journal: The Public Sector Innovation Journal, 21(2), 1-26.

Stevens, V., \& Verhoest, K. (2016b). A Next Step in Collaborative Policy Innovation Research: Analysing Interactions using Exponential Random Graph Modelling. The Innovation Journal: The Public Sector Innovation Journal, 21(2), 1-20.

Termeer, C., \& Nooteboom, S. (2014). Innovative leadership through networks. This is a chapter. In C. Ansell \& J. Torfing (Eds.). Public Innovation through Collaboration and Design (pp. 170-188). New York, N.Y.: Routledge.

Van Buuren, A., \& Loorbach, D. (2009). Policy innovation in isolation? Conditions for policy 


\section{Macrothink}

Journal of Public Administration and Governance

ISSN 2161-7104 2017, Vol. 7, No. 4

renewal by transition arenas and pilot projects. Public Management Review, 11(3), 375-392. https://doi.org/10.1080/14719030902798289

Vlaamse Bouwmeester. (2013). Metropolitaan Kustlandschap 2100: de ontwerpopgaven. Retrieved from the Vlaamse Bouwmeester website: https://tinyurl.com/y9ye26c3

Voets, J., Verhoest, K., \& Molenveld, A. (2015). Coordinating for Integrated Youth Care: The need for smart metagovernance. Public Management Review, 17(7), 1-21. https://doi.org/10.1080/14719037.2015.1029347

\section{Copyright Disclaimer}

Copyright for this article is retained by the author(s), with first publication rights granted to the journal.

This is an open-access article distributed under the terms and conditions of the Creative Commons Attribution license (http://creativecommons.org/licenses/by/4.0/). 